\title{
Surface renewal method for estimating sensible heat flux
}

\author{
MG Mengistu and MJ Savage* \\ Soil-Plant-Atmosphere Continuum Research Unit, School of Environmental Sciences, University of KwaZulu-Natal, \\ Pietermaritzburg, South Africa
}

\begin{abstract}
For short canopies, latent energy flux may be estimated using a shortened surface energy balance from measurements of sensible and soil heat flux and the net irradiance at the surface. The surface renewal (SR) method for estimating sensible heat, latent energy, and other scalar fluxes has the advantage over other micrometeorological methods since the method requires only measurement of the scalar of interest at a point and the method may be applied close to the canopy surface, thereby reducing fetch requirements. The SR analysis for estimating sensible heat flux from canopies involves highfrequency air-temperature measurements (typically 2 to $10 \mathrm{~Hz}$ ) using unshielded and naturally-ventilated $25-$ to $75-\mu \mathrm{m}$ diameter fine-wire thermocouples. The SR method is based on the premise that a parcel of air connected to the surface, after it has been enriched or depleted, is renewed by an air parcel from above. There are 2 SR analysis approaches: the ideal SR analysis approach which presumes a constant $\alpha$ factor; and a set of SR approaches that avoid the use of the $\alpha$ calibration factor. The weighting factor $\alpha$ depends on measurement height, canopy structure and stability conditions since it depends on the capability of the highest frequency eddies to mix the scalar within the air parcels renewed by coherent structures. A combination approach using SR and either similarity theory, that requires friction velocity or wind-speed measurements, or dissipation theory, has also been used to estimate $H$. The combination SR and dissipation method only requires high-frequency air-temperature data and may be considered not to require calibration. The ideal SR and combination SR/ dissipation approaches are the least expensive micrometeorological methods for estimating sensible heat flux and also latent energy flux if one forces closure of the surface energy balance. However, application of SR analysis using slow data-loggers require some expertise since high-frequency air temperature data are not usually stored with the slower data-loggers. Some structure functions can be stored for post-processing and determination of ramp amplitude and ramp period, but the appropriate time lags have to be chosen a priori. Fortunately, modern data-loggers avoid this problem and complex SR analysis approaches can now be applied. However, for routine purposes, applications using the ideal SR analysis approach with slow data-loggers may be of interest since it is a very affordable method.
\end{abstract}

Keywords: surface energy balance, sensible heat flux, latent energy flux, evaporation

\section{Introduction}

Accurate and routine measurement of latent energy flux $\lambda E$ is crucial in micrometeorology, agriculture and water resources management. In spite of this need, routine evaporation estimates over temporal and spatial scales are not yet readily available (Bezuidenhout et al., 2006; Jarmain et al., 2009). The latent energy flux may be estimated using a variety of techniques, including weighing lysimetry, soil-water monitoring, and micrometeorological methods. Lysimeters are too expensive and mainly used in agriculture. Soil-water monitoring is labour intensive and is often inaccurate unless averaged over a long period of time. Micrometeorological methods for estimating scalar fluxes, such as eddy covariance, Bowen ratio energy balance, surface renewal, flux variance, and optical scintillation methods, do not disturb the microenvironment and they minimise sampling problems by integrating fluxes over a large area. The eddy covariance (EC) method directly measures the turbulence, but it is stringent (Drexler et al., 2004), and requires many post-processing corrections, favourable wind directions, careful sensor positioning and alignment. The Bowen ratio energy balance (BREB) and the flux variance methods are limited by constraints imposed by extensive fetch

\footnotetext{
* To whom all correspondence should be addressed.

祍 +2733260 5510; fax: +2733 260 5514; e-mail: savage@ukzn.ac.za

Received 18 September 2008; accepted in revised form 15 December 2009.
}

requirements with the latter based on Monin-Obukhov similarity theory (MOST) which refers to an atmospheric layer over an extensive flat and homogeneous surface. The surface layer consists of a roughness sub-layer adjacent the surface and an inertial sub-layer above that. MOST applies to the inertial sub-layer. The scintillation method provides pathaveraged estimates of sensible heat flux (see e.g. Hill, 1992; Hill et al., 1992; Thiermann and Grassl, 1992; Green et al., 1994; De Bruin et al., 1995; Anandakumar, 1999; Meijninger and De Bruin, 2000; Savage et al., 2004; Savage, 2009; Savage et al., 2010). A scintillometer is a device that optically measures the intensity fluctuations of visible or infrared radiation, caused by interference due to inhomogeneities of the refractive index of air along the path of propagation (Hill, 1992). In contrast to point measurements, displaced-beam scintillometers combined with MOST provide path-averaged measurements of sensible heat and momentum fluxes over distances of between $50 \mathrm{~m}$ and $250 \mathrm{~m}$ (Thiermann and Grassl, 1992) although distances of up to $350 \mathrm{~m}$ have been used (Savage, 2009). Nevertheless, the cost of the scintillometer is high. Despite the availability of different methods for estimating $\lambda E$ directly or indirectly (i.e. by forcing closure of the energy balance), based on the assumptions made, accuracy, simplicity, spatial representation, robustness, fetch requirements, and cost, each method has advantages and disadvantages. Thus the search for methods integrating most of the advantages and avoiding most of the disadvantages is a matter of intensive research. 


\section{Radiation and energy balances: the shortened energy balance method}

Solar radiation is a significant source of energy available at the earth's surface used for heating the air and soil, evaporating water, and driving photosynthesis within the earth-atmosphere system (Campbell and Diak, 2005). Net irradiance is the difference between the sum of all incoming and sum of all outgoing irradiances at the earth's surface (Arya, 2001). For a smooth, horizontal, homogeneous, and extensive surface, net irradiance $R_{n}$ is the sum of the incoming shortwave $I_{s}$ and infrared $L_{d}$ irradiances, less the reflected shortwave $r \cdot I_{s}$ and emitted infrared $L_{u}$ irradiances:

$$
R_{n}=I_{s}-r \cdot I_{s}+L_{d}-L_{u}
$$

Net irradiance, typically expressed in $\mathrm{W} \cdot \mathrm{m}^{-2}$, is the major source of energy flux for heating and cooling at the surface of the earth and is one of the major components of the surface energy balance.

To reduce the cost in estimating $\lambda E$, micrometeorological methods for estimating sensible heat flux are combined with the energy balance equation. The shortened energy balance equation for a short and flat surface is expressed as:

$$
R_{n}=G+H+\lambda E
$$

where:

$R_{n}$ is the net irradiance

$G$ the soil heat flux

$H$ the sensible heat flux where advection is assumed to be negligible

The energy flux associated with photosynthesis and respiration, and energy flux stored in plant canopies are usually small compared with the other terms (Thom, 1975).

\section{Historical development of the surface renewal method}

Surface renewal $(S R)$ theory was originally developed in the field of chemical engineering by Higbie (1935) to investigate interfacial heat transfer between a liquid and a gas and the SR analysis to estimate scalar exchange in the vegetationatmosphere interface was originally conceived as a simple 'transilient' theory (Stull, 1984) that is Lagrangian in nature and based on the scalar conservation equation (Paw $\mathrm{U}$ et al., 1995; Castellví, 2009). This theory arises from the concept that turbulent exchange can be described as the exchange of air parcels from a known height to another, with weighting factors assigned to the fraction of exchange to a height from each of many other heights (Paw U et al., 2005). Scalars such as air temperature, water vapour pressure, carbon dioxide concentration, for which SR theory could be applied, would have relevance in biometeorology.

Several studies have reported on the use of the SR analysis for estimating $H$ above different surfaces in the past decade. The original SR method as used by Snyder et al. (1996) must be calibrated against another standard method, such as the EC method. Currently, the most used SR analysis approaches are: an ideal SR analysis equation that only requires the temporal trace of the scalar as input (Snyder et al., 1996; Chen et al., 1997a) and the other SR analysis equations that require the temporal trace of the scalar and friction velocity as inputs (Chen et al., 1997b; Castellví et al., 2002; Castellví, 2004). Combination

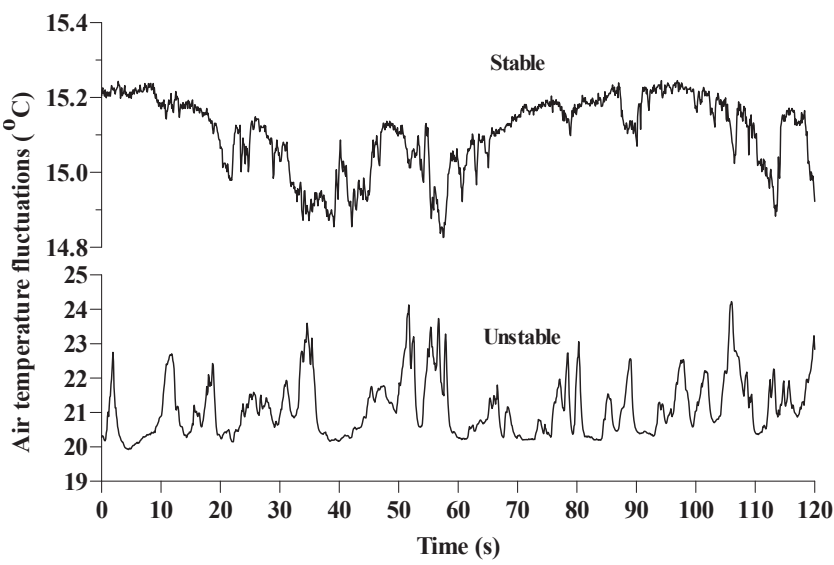

Figure 1

Air-temperature ramps observed in a sample of $120 \mathrm{~s}$ of $10 \mathrm{~Hz}$ air-temperature traces. The measurements were taken at $0.5 \mathrm{~m}$ above grass (0.3 $\mathrm{m}$ tall) for unstable (10:00) and stable conditions (01:00), in the Bellevue area neighbouring Ashburton and close to Pietermaritzburg, South Africa for day of year 321 (2003)

approaches, for example, using SR/similarity and SR/dissipation methods have also been used, by Castellví (2004) and Castellví and Snyder (2009a) respectively. The SR/similarity combination method requires calibration and also wind speed measurements whereas Castelví and Snyder (2009a) showed that the SR/dissipation method requires only air-temperature trace measurements.

Surface renewal analysis is a relatively new, low-cost, attractive and simple method for estimating scalar fluxes (Paw U et al., 1995; Snyder et al., 1996; Spano et al., 1997a, b, 2000; Savage et al., 2004; Paw U et al., 2005; Castellví et al., 2006a, 2008; Castellví, 2007). For estimating sensible heat flux, high frequency air temperature measured at a point in the flow using unshielded and naturally-ventilated fine-wire thermocouples is required as an input for the ideal SR approach and the SR combination approaches. The low cost of the method allows for replication of the method in field trials (Snyder et al., 2008).

The SR analysis is based on the premise that an air parcel from above sweeps to the surface and replaces a parcel that has been enriched (depleted) of scalar during its contact with the sources (sinks). Therefore the air parcel is ejected from the canopy scalar into the atmosphere. Coherent structures (Fig. 1) are responsible for transport of momentum, heat and other scalar quantities (Raupach et al., 1989; 1996; Qui et al., 1995). Temperature traces, typically between $2 \mathrm{~Hz}$ and 10 $\mathrm{Hz}$ often exhibit organised coherent structures which resemble ramp events (Bergström and Högström, 1989; Gao et al., 1989; Shaw et al., 1989; Paw U et al., 1992). The analysis of the observed ramp events in temperature traces is required to estimate $H$ (Paw U et al., 1992). The use of air-temperature structure functions was suggested by Van Atta (1977) and Chen et al. (1997b). Low-pass filtering techniques (Paw U et al., 1995; Katul et al., 1996) and other techniques such as wavelet transforms have also been used to extract the air-temperature ramp amplitude and ramp period. The ideal SR analysis equation (Snyder et al., 1996) only requires the trace as an input. Therefore, for estimation of $H$, only air-temperature measurements are required but the method requires calibration against a standard method such as eddy covariance.

Chen et al. (1997b) presented a new $3^{\text {rd }}$ order structure function for estimating $H$ that uses the zero plane displacement 
and friction velocity as inputs. Castellví et al. (2002) proposed a new method that combined SR analysis and similarity theory. Castellví (2004) explained the companion method presented by Castellví et al. (2002) and derived a new method that is exempt from calibration. However, unlike the ideal SR analysis, the methods proposed by Chen et al. (1997a) and Castellví (2004) also require wind-speed measurements. Using a result from Hsieh and Katul (1997) concerning the dissipation method which is based on turbulent kinetic energy, scalar variance and MOST, Castellví and Snyder (2009a) used a combination SR/ dissipation method which appears to be exempt from calibration requiring only measurements at frequencies of between 4 and $10 \mathrm{~Hz}$.

If $\lambda E$ is obtained as the residual of the shortened energy balance equation (Eq. (2)), $H$ estimated using SR analysis is convenient since it operates either in the roughness or the inertial sub-layers and it is relatively inexpensive. In the next section, the most commonly-used SR approach will be described in detail.

\section{Ideal surface renewal analysis model based on an air-temperature structure function analysis}

Paw $U$ et al. (1995) expressed $H$ as the change in heat energy content of air with time across a unit horizontal area:

$$
H=\alpha \rho c_{p} \frac{d T}{d t} \frac{V}{A}
$$

where:

$\alpha$ is a weighting factor (regression coefficient fit to the above equation when $H$ is measured independently using a standard method such as EC)

$\rho$ the density of air $\left(\mathrm{kg} \cdot \mathrm{m}^{-3}\right)$

$c$ the specific heat capacity of air $\left(\mathrm{J} \cdot \mathrm{kg}^{-1} \cdot \mathrm{K}^{-1}\right)$

$\stackrel{p}{d T / d t}$ the rate of change in air temperature $\left({ }^{\circ} \mathrm{C} \cdot \mathrm{s}^{-1}\right)$

$V / A$ the volume of air per unit horizontal area

If the air-temperature measurement is taken at canopy height, then $V / A$ (which is equal to the vertical distance) will be the canopy height $(h)$. High frequency air-temperature data are measured at a fixed point and hence the use of Eq. (3) assumes that $d T / d t$ is approximately equal to $d T / d t$ and internal advection is negligible (Paw $\mathrm{U}$ and Brunet, 1991; Paw U et al., 1995). This assumed proportional relationship between the advective term $d T / d t$ and the total derivative $d T / d t$ has been discussed in detail by Paw $\mathrm{U}$ et al. (1995). However, this assumption may not be correct under all conditions. For example, the assumption may be invalid when there is strong local advection and under high wind shear close to the canopy top of low vegetation and soil surface (Snyder et al., 1996). Low-pass filtering techniques were used by Paw U et al. (1995) to smooth the high frequency air-temperature data to remove the internal advection and to determine $H$. However, the filtering technique is cumbersome, due to the necessity of choosing filtering functions and use of numerical methods to identify scalar increases or decreases (Paw U et al., 2005).

When high frequency air-temperature measurements are taken at a point at or above the canopy top, ramps are observed (Fig. 1) in the air-temperature traces. These air- temperature ramps are characterised by an amplitude $a\left({ }^{\circ} \mathrm{C}\right)$, a ramp period $L_{r}$ (s) where the change in air temperature with time occurs, and a quiescent period $L_{q}$ (s) for which there is no change in air temperature with time (Snyder et al., 1996, 1997).
The total ramp duration $\tau(\mathrm{s})$ is the sum of ramp period $L_{r}$ and quiescent period $L_{q}$ (Fig. 2). The amplitude $a$ is positive when the atmosphere is unstable and (the sign of $H$ is positive) and $a$ is negative for stable atmospheres ( $H$ is negative).

For estimating $H$, Paw $\mathrm{U}$ et al. (1995) simplified and modified the SR analysis by substituting $d T / d t$ in Eq. (3) by $a / \tau$ $\left({ }^{\circ} \mathrm{C} \cdot \mathrm{s}^{-1}\right)$ for the average rate of change in air temperature for the total ramp period:

$$
H=\alpha \rho c_{p} \frac{a}{L_{r}+L_{q}} z
$$

where:

$\alpha$ is a weighting factor accounting for the spatially-averaged (vertical) air-temperature derivative from the bottom to the top of the air parcel (a correction factor for unequal heating or cooling below the sensor)

The weighting factor $\alpha$ depends on $z$ (which is the measurement height), canopy structure and atmospheric stability conditions. According to Castellví and Snyder (2009a), the factor $\alpha$ is a measure of the capability of the turbulence to mix the scalar within the air parcel to be renewed. Also in the factor $\alpha$, one may include other aspects such as thermocouple size and the frequency available to determine the ramp parameters (Snyder et al., 1996; Spano et al., 1997a, b, 2000; Paw U et al., 2005). Generally, for near-neutral conditions, $\alpha=0.5$ as shown over mixed deciduous forest, Walnut orchard, and maize canopies (Table 1, next page) for measurements taken at canopy height (Paw U et al., 1995). For a short turf grass ( $0.1 \mathrm{~m}$ tall), excellent estimates of $H$ were obtained using $\alpha=1$, when the measurements are taken in the inertial sub-layer for mainly unstable conditions (Snyder et al., 1996).

Snyder et al. (1996) used structure functions of air temperature and the analysis technique of Van Atta (1977) to estimate the amplitude $a$ and the ramp period $\tau=L_{r}+L_{q}$ as shown in Fig. 2. The structure function value $S^{n}(r)$ is calculated for each averaging period, typically sub-hourly, from high-frequency

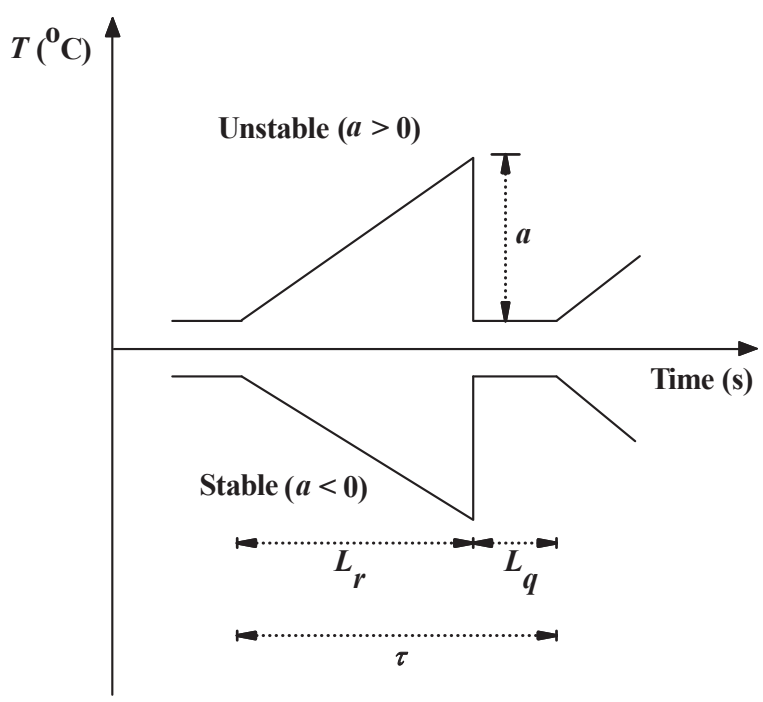

Figure 2

An ideal surface renewal analysis ramp model, assuming a sharp instantaneous drop in air temperature with amplitude a $>0$ for unstable and $a<0$ for stable atmospheric conditions. The ramp period is $L_{r}$ and $L_{q}$ the quiescent time period with $\tau=L_{r}+L_{q}$ the total ramp period (inverse ramp frequency) 


\begin{tabular}{|c|c|c|c|c|c|c|c|}
\hline \multicolumn{8}{|c|}{$\begin{array}{l}\text { TABLE } 1 \\
\text { The weighting factor } \alpha \text { for a range of surfaces using different time lags and sensor sizes during unstable } \\
\text { conditions. The slope of the regression of } H \text { estimated using the SR method vs. } H \text { obtained using a standard } \\
\text { method (eddy covariance) yields } \alpha \text { for linear fits forced throuh the origin. }\end{array}$} \\
\hline Surface & $\begin{array}{l}\text { Canopy } \\
\text { height } \\
\text { (m) }\end{array}$ & $\begin{array}{l}\text { Height above } \\
\text { canopy }(\mathrm{m})\end{array}$ & $\begin{array}{c}\text { Sensor } \\
\text { size } \\
(\mu \mathrm{m})\end{array}$ & $\begin{array}{c}\text { Sampling } \\
\text { frequency } \\
\text { (Hz) }\end{array}$ & $\begin{array}{l}\text { Time } \\
\text { lag } \\
r(s)\end{array}$ & $\alpha$ & Authors \\
\hline Bare-soil & 0.00 & - & 12.7 & 8 & 0.25 & 0.90 & Duce et al. (1998) \\
\hline Bare-soil & 0.00 & - & 25.4 & 8 & 0.25 & 1.04 & Duce et al. (1998) \\
\hline Bare-soil & 0.00 & - & 76.2 & 8 & 0.25 & 1.88 & Duce et al. (1998) \\
\hline Bare-soil & 0.00 & 0.03 & 25.0 & 10 & 0.10 & 0.69 & Chen et al. (1997b) \\
\hline Endorreic salty lagoon & 0.00 & 0.90 & 76.2 & 8 & 0.75 & 1.00 & Zapata and Martínez-Cob (2001) \\
\hline Open water & 0.00 & $1.0,1.3,1.9,2.6$ & 75 & 10 & $0.4,0.8$ & $0.2,0.25$ & Mengistu and Savage (2010) \\
\hline Mulch & 0.05 & 0.09 & 25.0 & 10 & 0.10 & 0.51 & Chen et al. (1997b) \\
\hline Grass (alta fescue) & 0.10 & 0.35 & 76.2 & 8 & 0.75 & 1.00 & Snyder et al. (1996) \\
\hline Grass (alta fescue) & 0.10 & 0.30 & 76.2 & 8 & 0.25 & 0.97 & Duce et al. (1997) \\
\hline Irrigated pasture (tall fescue) & 0.08 to 0.12 & $0.75(0.6)$ & 75 & 4 & $0.25,0.5$ & $0.35(0.4)$ & Snyder et al. (2008) \\
\hline Wheat & 0.70 & 0.30 & 76.2 & 8 & 0.50 & 1.00 & Duce et al. (1997) \\
\hline Sorghum & 0.70 & 0.30 & 76.2 & 8 & 0.75 & 1.02 & Duce et al. (1997) \\
\hline Wheat & 0.90 & 0.50 & 25.4 & 16 & 0.30 & 1.00 & Anandakumar (1999) \\
\hline Sugarcane & $>1 \mathrm{~m}$ & $0.2,0.5,0.75,1.5$ & 75 & 10 & $0.4,0.8$ & 0.55 to 0.66 & Nile (2010) \\
\hline Sparse grape vine & 2.20 & 0.00 & 76.2 & 8 & 0.50 & 0.87 & Spano et al. (1997b) \\
\hline Maize & 2.60 & 0.00 & 12.5 & 10 & 0.10 & 0.50 & Paw U et al. (1995) \\
\hline Peach orchard & 3.95 & 1.55 & Sonic temperature & 10 & Several & 0.95 & Castellví and Snyder (2009) \\
\hline Citrus & 4 to 4.5 & 0 to 0.5 & 76.2 & 4 & $0.5,1.0$ & 0.227 & Snyder and O'Connell (2007) \\
\hline Avocado & 5.20 & 0.00 & 76.2 & 8 & 0.50 & 0.59 & Spano et al. (1997b) \\
\hline Walnut orchard & 6.00 & 0.00 & 12.5 & 10 & 0.10 & 0.50 & Paw U et al. (1995) \\
\hline Flood-irrigation pecan & 12.8 & $-3.7,0$ & - & 4 & 1.0 & \begin{tabular}{|l|}
$1.1(z=d)$ \\
$0.5(z=h)$ \\
\end{tabular} & Simmons et al. (2007) \\
\hline Douglas-fir forest & 16.70 & 6.30 & 25.0 & 2 & 0.50 & 0.52 & Chen et al. (1997b) \\
\hline Mixed deciduous forest & 18.00 & 0.00 & 12.5 & 10 & 0.10 & 0.50 & Paw U et al. (1995) \\
\hline
\end{tabular}

air-temperature measurements at frequency $f(\mathrm{~Hz})$ using the relation:

$$
S^{n}(r)=\frac{1}{m-j} \sum_{i=1+j}^{m}\left(T_{i}-T_{i-j}\right)^{n}
$$

where:

$m$ is the number of data points in the averaging period $n$ is the power of the function

$j$ is the number of time lags between data points corresponding to a time lag (s)

$r=j / f$

$T_{i}$ is the $i^{\text {th }}$ temperature sample

Van Atta (1977) suggested that $\tau$ must be much less than $r$, typically $\tau>10 \tau$, or otherwise the structure-function theory is invalid. Snyder et al. (2007) used the condition that $\tau>5 \tau$ and imposed an upper limit for $\tau$ of $600 \mathrm{~s}$.

The Van Atta (1977) method involves estimating the mean value for amplitude $a$ during the time interval by solving the following equation for real roots:

$$
a^{3}+p a+q=0
$$

where:

$$
p=10 S^{2}(r)-\frac{S^{5}(r)}{S^{3}(r)}
$$

and

$$
q=10 S^{3}(r)
$$

The ramp period $\tau$ is calculated using:

$$
\tau=-\frac{a^{3} r}{S^{3}(r)}
$$

The disadvantage of using a fixed $\alpha$ (Eq. (4)) is that the ideal SR method measurements of $H$ must be calibrated using EC estimates. Slow data-loggers are limited and the weighting factor $\alpha$ depends on the time lag used (Snyder et al., 1996; Zapata and Martínez-Cob, 2001). The size of the air-temperature sensor affects the amplitude $a$ and the ramp period $\tau$, and hence $\alpha$. The sensor time constant represents the time it takes for the sensor to respond to $63.2 \%$ of a step change in temperature. For a $75-\mu \mathrm{m}$ diameter sensor for example, the time constant is $50 \mathrm{~ms}$ for low air flow (Medtherm, 2007). Therefore, the use of 75- $\mu \mathrm{m}$ diameter sensors, in general, is adequate for air-temperature measurements for the SR method. The $\alpha$ values for various surfaces using different time lags $r$ and sensor sizes are shown in Table 1, for unstable atmospheric conditions.

Once the weighting factor $\alpha$ is determined for a particular canopy, it is stable and does not change from site to site regardless of the weather conditions (Drexler et al., 2004) unless there are considerable changes in vegetation canopy structure (Paw U et al., 1995; Snyder et al., 1996; Spano et al., 2000). The parameter $\alpha$ increases to some extent with increase in temperature-sensor size and this can cause a problem related to sensitivity of the SR model to slower response scalar sensors (Paw U et al., 2005). 


\section{Surface renewal analysis using a ramp model with finite micro-front period}

Chen et al. (1997a) proposed a more realistic ramp model, which takes into consideration a finite micro-front period $L_{f}$ instead of a sharp decrease in air temperature (Fig. 3), and assumes an insignificant quiescent period $L_{q}$ to avoid numerical complexity. The quiescent period exists, but when the model takes into account the quiescent period between the micro-front and formation of the next ramp, there were no significant changes in the sensible heat flux estimates.

Because very high frequencies are required to determine $\boldsymbol{L}_{f}$, the approach estimates the amplitude $a$ and total ramp duration $\tau=L_{r}+L_{f}$, from fluctuations of high-frequency airtemperature measurements using a cubic temperature structure function as:

$$
\frac{a}{\tau^{1 / 3}}=-\gamma\left(\frac{S_{\left(r_{m}\right)}^{3}}{r_{m}}\right)^{1 / 3},
$$

where:

$S^{3}{ }_{\left(r_{m}\right)}$ is the $3^{\text {rd }}$ order of the structure function for temperature

$r_{m}$ is the sampling time lag at which $-\left(S^{3}{ }_{(r)} / r\right)^{1 / 3}$ is a maximum

$\gamma$ is a coefficient which corrects for the difference between $a / \tau^{1 / 3}$ and the maximum value of $-\left(S_{(r)}^{3} / r\right)^{1 / 3}$

Raupach et al. (1989) predicted that for canopies $1 / \tau$ should scale with maximum wind shear $(d u / d z$ at $z=h$, where $u$ is the mean wind speed and $h$ the canopy height). In the canopy and roughness sub-layer, transport of momentum and scalar fluxes are dominated by eddies of length scale comparable to $h$, while in the inertial sub-layer, dominant eddies scale with $z-d$, where $d$ is zero-plane displacement height (Raupach et al., 1996; Chen et al., 1997b).

Chen et al. (1997b) scaled $1 / \tau$ as follows:

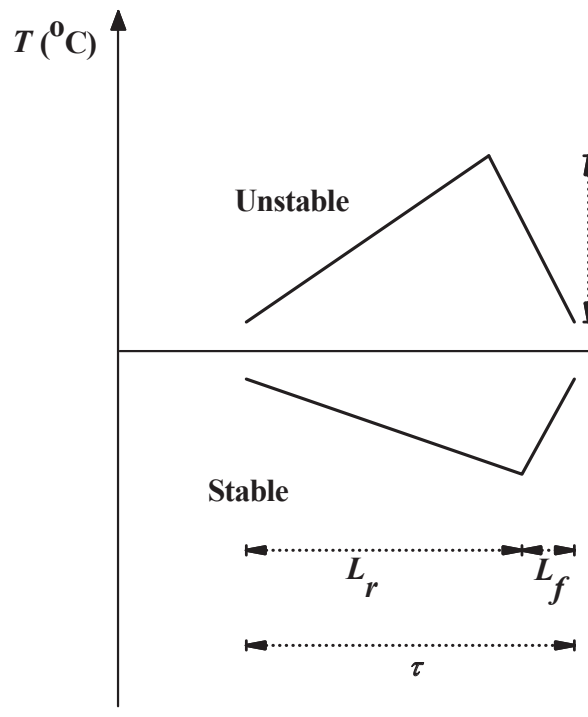

Figure 3

Surface renewal analysis ramp model which assumes a finite micro-front time, where $a$ is the air-temperature amplitude, $L_{r}$ is the ramp period, $L_{f}$ is the micro-front period, and $\tau$ is the total ramp period

$$
\frac{1}{\tau}=\left\{\begin{array}{l}
\beta \frac{u_{*}}{h}, 0.2 h<z \leq h+2(h-d), \\
\beta \frac{u_{*}}{z-d}, z>h+2(h-d) \text { or } z \leq 0.2 h,
\end{array}\right.
$$

where:

$\beta$ is an empirical coefficient

$u_{*}$ the friction velocity $\left(\mathrm{m} \cdot \mathrm{s}^{-1}\right)$

Following Sellers et al. (1986), the roughness sub-layer is assumed to be between $z=h$ and $z=h+2(h-d)$. The layer adjacent to the soil within canopies $(z \leq 0.2 h)$ is treated the same way as the inertial sub-layer, with appropriate $u_{*}$ and $h$ for the soil or canopy understory (Lee and Black, 1993).

Chen et al. (1997b) recommended that for routine application of the finite micro-front SR model, only the maximum of $-\left(S^{3}{ }_{(r)} / r\right)^{1 / 3}$ is required from high-frequency air- temperature data. According to the model, $H$ is proportional to $z / h^{2 / 3}$ in the roughness sub-layer and proportional to $z /(z-d)^{2 / 3}$ in the inertial sub-layer. Substituting expressions for $a$ and $\tau$ from Eqs. (10) and (11) into Eq. (4) to obtain $H$ yields:

$H=\left\{\begin{array}{l}-\alpha \beta^{2 / 3} \gamma \rho c_{p}\left(\frac{S_{\left(r_{m}\right)}^{3}}{r_{m}}\right)^{1 / 3} u_{*}^{2 / 3} \frac{z}{h^{2 / 3}}, 0.2 h<z \leq h+2(h-d), \\ -\alpha \beta^{2 / 3} \gamma \rho c_{p}\left(\frac{S_{\left(r_{m}\right)}^{3}}{r_{m}}\right)^{1 / 3} u_{*}^{2 / 3} \frac{z}{(z-d)^{2 / 3}}, z>h+2(h-d) \text { or } z \leq 0.2 h .\end{array}\right.$

The empirical combined coefficient $\alpha \beta^{2 / 3} \gamma$ is a common factor in both roughness and inertial sub-layers. Chen et al. (1997b) found a roughly constant value of 0.4 for the combined coefficient $\alpha \beta^{2 / 3} \gamma$ (Table 2), in their experiments on Douglas-fir forest, bare soil, and straw mulch.

Sensible heat flux may be estimated from the average cubic temperature structure function (using high-frequency airtemperature data) and measured or estimated friction velocity within the canopy and roughness sub-layers and inertial sublayer, using this model for stable and unstable conditions. The approach does not require calibration but additional measurement of horizontal wind speed is needed and slow data-loggers may be limited in determining the $3^{\text {rd }}$ order air-temperature structure function.

\section{Combined surface renewal analysis model and similarity theory}

Castellví et al. (2002) proposed an SR analysis model based on a turbulent diffusion approach (similarity theory), to estimate $H$ using high-frequency air-temperature data, friction velocity, and similarity formulae. Similarity theory describes $H$ as:

$$
H=\rho c_{p} K_{h} \frac{d T}{d z}
$$

\begin{tabular}{|l|c|c|c|c|}
\hline \multicolumn{5}{|c|}{ TABLE 2} \\
$\begin{array}{c}\text { Average coefficients } \alpha, \beta, \gamma \text { and the combined } \\
\text { coefficient } \alpha \beta^{2 / 3} \gamma \text {, for Douglas-fir forest, straw } \\
\text { mulch, and bare soil (Chen et al., 1997b) }\end{array}$ \\
\hline Canopy & $\alpha$ & $\beta$ & $\gamma$ & $\alpha \beta^{2 / 3} \gamma$ \\
\hline Douglas-fir forest & 0.527 & 0.795 & 1.001 & 0.418 \\
\hline Straw mulch & 0.511 & 0.538 & 1.175 & 0.397 \\
\hline Bare soil & 0.691 & 0.398 & 1.104 & 0.413 \\
\hline
\end{tabular}


where:

$K_{h}$ is the turbulent transfer coefficient $\left(\mathrm{m}^{2} \cdot \mathrm{s}^{-1}\right)$ or eddy diffusivity for $H$

$T$ the average air temperature $(K)$ during the measurement time

$z$ the height above the surface (m)

Invoking Eq. (4) for the ideal SR model (Paw U et al., 1995), the variable $\alpha z$ represents the 'effective eddy size' responsible for the air-parcel renewal (Castellví et al., 2002; Castellví, 2004). Since ramp-like structures (characterised by amplitude $a$ and total ramp duration $\tau$ ) contribute to vertical transport, Castellví et al. (2002) proposed the following relationship:

$$
\begin{aligned}
& \frac{a}{\alpha z} \propto \frac{\partial T}{\partial z}=\beta \frac{a}{z}, \text { for the roughness sub-layer } \\
& \frac{a}{\alpha z} \propto \frac{\partial T}{\partial z}=\beta \frac{a}{z-d}, \text { for the inertial sub-layer }
\end{aligned}
$$

where:

$\beta$ is a scale or link parameter (not to be confused with $\beta$ in Eq. (11))

$d$ the zero-plane displacement height - normally taken as $2 h / 3$ where $h$ is the canopy height

When measurements are taken well above the canopy top in the inertial sub-layer, MOST can be used to express $K_{h}$ as follows:

$$
K_{h}=k u_{*}(z-d) / \phi_{h}(\zeta)
$$

where:

$k$ is the von Kármán constant (0.41)

$\phi_{h}(\zeta)$ is the stability function for sensible heat flux where

$\zeta=(z-d) / L$ is a dimensionless buoyancy (stability)

parameter

$L$ is the Obukhov length (m):

$L=\frac{T}{k g} \frac{\rho c_{p} u_{*}^{3}}{\left(H+0.61 c_{p} T E\right)}$

Following Businger et al. (1971), the stability function $\phi_{h}(\zeta)$ is:

$$
\begin{aligned}
& \text { unstable } \phi_{h}(\zeta)=0.74 / \sqrt{1-9 \zeta} \\
& \text { neutral } \phi_{h}(\zeta)=0.74 \\
& \text { stable } \phi_{h}(\zeta)=0.74+4.7 \zeta
\end{aligned}
$$

Castellví et al. (2002) proposed the following relationship to estimate $H$ in the inertial and roughness sub-layers by combining Eqs. (14) to (16) to yield:

$$
H= \begin{cases}\rho c_{p} \beta_{2} a u_{*}, & \text { roughness sublayer } \\ \rho c_{p} \beta_{1} a u_{*} / \phi_{h}(\zeta), & \text { inertial sublayer }\end{cases}
$$

where:

amplitude $\beta_{1}$ is a scale parameter for the inertial sub-layer $\beta_{2}$ is a scale parameter for the roughness sub-layer $a$ is determined using the Van Atta (1977) approach with $u$ * and $\zeta$ determined by iteration

Castellví et al. (2002) found $\beta_{1}$ values ranging from 0.10 to 0.15 and $\beta$, values ranging from 0.23 to 0.33 above grass, wheat, and grapevine canopies for measurements taken in inertial and roughness sub-layers.

Castellví (2004) derived the following relationship for estimating the weighting factor $\alpha$ in Eq. (4) for measurements above the canopy:

$$
\alpha= \begin{cases}\left(\frac{k}{\pi} \frac{(z-d)}{z^{2}} \frac{\tau u_{*}}{\phi_{h}(\zeta)}\right)^{1 / 2}, & z-d>z^{*} \\ \left(\frac{k}{\pi} \frac{z^{*}}{z^{2}} \frac{\tau u_{*}}{\phi_{h}(\zeta)}\right)^{1 / 2}, & h \leq z-d \leq z^{*}\end{cases}
$$

where:

$z^{*}$ is the roughness sub-layer depth.

Combining Eqs. (4) and (18), Castellví (2004) proposed the following expression for estimating sensible heat flux:

$H= \begin{cases}\rho c_{p}\left(\frac{a}{\tau^{1 / 2}}\right)\left(\frac{k(z-d)}{\pi}\right)^{1 / 2}\left(\frac{u_{*}}{\phi_{h}(\zeta)}\right)^{1 / 2}, & z-d>z^{*} \\ \rho c_{p}\left(\frac{a}{\tau^{1 / 2}}\right)\left(\frac{k z^{*}}{\pi}\right)^{1 / 2}\left(\frac{u_{*}}{\phi_{h}(\zeta)}\right)^{1 / 2}, & h \leq z-d \leq z^{*}\end{cases}$

Equation (19) is valid when measurements are made over homogeneous canopies but good performance has been observed over heterogeneous canopies (Castellví et al., 2006b). In particular, however, the relationship is exempt from calibration regardless of the stability conditions (Castellví, 2004). Also by combining Eqs. (18) and (19), and invoking the relationship between the ramp period and amplitude (Eq. (10)) from the micro-front model, Castellví (2004) derived the following relationship to estimate sensible heat flux (Similar relationships are presented by Castellví and Martínez-Cob (2005) but there is a misprint in their Eqs. (5) and (6) which contains $k(z-d)^{4 / 5}$ instead of the correct term $\left.(k(z-d))^{4 / 5}\right)$ :

$H= \begin{cases}\rho c_{p}\left(\frac{g}{T}\right)^{1 / 5} \frac{(k(z-d))^{4 / 5}}{\pi^{3 / 5}}\left(-\gamma^{3} \frac{S_{\left(r_{m}\right)}^{3}}{r_{m}}\right)^{3 / 5} \frac{1}{a^{3 / 5}}\left(\frac{1}{-\zeta \phi_{h}^{3}(\zeta)}\right)^{1 / 5}, & \begin{array}{c}\text { (20) } \\ \text { (1) }\end{array} z^{*} \\ \rho c_{p}\left(\frac{g}{T}\right)^{1 / 5} k^{4 / 5}\left(\frac{z^{*}}{\pi}\right)^{3 / 5} z^{1 / 5}\left(-\gamma^{3} \frac{S_{\left(r_{m}\right)}^{3}}{r_{m}}\right)^{3 / 5} \frac{1}{a^{3 / 5}}\left(\frac{1}{-\zeta \phi_{h}^{3}(\zeta)}\right)^{1 / 5}, & h \leq z-d \leq z^{*}\end{cases}$

Equation (20) depends on the stability parameter $\zeta$, and hence wind speed measurements are also required as an input. If one uses slow data-loggers, the method is not totally exempt from calibration because of parameter $\gamma$ (Castellví, 2004; Castellví and Martínez-Cob, 2005). However, $\gamma$ varies by less than $25 \%$ with respect to unity for different canopies (Chen et al., 1997b). Equation (20) performed well using $\gamma=1.1$ (Table 2) for measurements taken at different heights above the canopy (Castellví and Martínez-Cob, 2005). The function $\left(-\zeta \phi^{3}{ }_{h}(\zeta)\right)^{-1 / 5}$ in Eq. (20) can be set to approximately 2.4 for the stability range $-3 \leq \zeta \leq-0.03$, with a relative error of less than $8.5 \%$ and can be expressed as (Castellví, 2004):

$H= \begin{cases}2.4 \rho c_{p}\left(\frac{g}{T}\right)^{1 / 5} \frac{(k(z-d))^{4 / 5}}{\pi^{3 / 5}}\left(-\gamma^{3} \frac{S_{\left(r_{m}\right)}^{3}}{r_{m}}\right)^{3 / 5} \frac{1}{a^{3 / 5}}, & z-d>z^{*} \\ 2.4 \rho c_{p}\left(\frac{g}{T}\right)^{1 / 5} k^{4 / 5}\left(\frac{z^{*}}{\pi}\right)^{3 / 5} z^{1 / 5}\left(-\gamma^{3} \frac{S_{\left(r_{m}\right)}^{3}}{r_{m}}\right)^{3 / 5} \frac{1}{a^{3 / 5}}, & h \leq z-d \leq z^{*}\end{cases}$

Equation (21) holds under slightly unstable conditions, is valid in both the roughness and inertial sub-layers, only requires air-temperature data as an input, and may be considered exempt from calibration (Castellví, 2004) since $\beta_{1}$ in Eq. (17), approximately 0.1 , is appropriate under unstable conditions over a variety of canopies. For both roughness and inertial layers, Castellví (2004) found that the value of 0.1 was robust with height.

The main advantage of this SR analysis combination approach therefore is that it is not sensitive to measurement 
height, and furthermore that it is based on the fact that vertical velocity of the mean eddies responsible for the renewal process has been properly scaled for the corresponding amplitude of the air temperature of the mean ramp events (Castellví et al., 2002).

\section{Combined surface renewal analysis model and dissipation theory}

An analysis of combining the SR method with dissipation theory was presented by Castellví and Snyder (2009a). For the dissipation method, the normalised dissipation rate for scalar $s$ can be expressed as

$$
\Phi_{s}(\zeta)=\frac{k(z-d)}{u_{*} s_{*}^{2}} \varepsilon_{s}
$$

where:

$S_{*}$ is the scalar surface scale

$\varepsilon_{s}$ is the mean dissipation rate for scalar $s$

where:

$$
u_{*} S_{*}=\left(\frac{k(z-d) u_{*}}{\Phi_{s}(\zeta) \varepsilon_{s}}\right)^{\frac{1}{2}}
$$

Using a result of Hsieh and Katul (1997), which involved combining dimensional analysis and the traditional dissipation method, Castellví and Snyder (2009a) showed that:

$$
u_{*} s_{*}=\frac{1.66}{\pi}(z-d) \frac{a_{s}^{2}}{\tau_{s} \sigma_{s}}
$$

where:

$\sigma_{s}$ is the scalar standard deviation

For sensible heat flux, then:

$$
\alpha=\frac{1.66}{\pi} \frac{(z-d)}{z} \frac{a}{\sigma_{T}}
$$

They note that the new dissipation-SR analysis, based on Eq. (24), does not require $\varepsilon_{s}$ as an input and does not depend on stability or on any similarity relationships. Furthermore, for sensible heat flux, only air temperature at frequencies of between $4 \mathrm{~Hz}$ and $10 \mathrm{~Hz}$ are required. They contend that the constant 1.66 does not depend on height. Further research on this aspect is required.

\section{Application of the SR method}

Most often, crop coefficients are obtained using lysimeters to measure the evaporation and simultaneously, short-grass (or tall-crop) reference is calculated from weather data. Using SR to estimate sensible heat flux, from which evaporation was calculated using measurements of net irradiance and soil heat flux, Snyder and O'Connell (2007) obtained crop coefficients of micro-sprinkled irrigated citrus for 4 years. A similar method for estimating irrigated pasture evaporation was applied by Snyder et al. (2008) for 8 months. For a 2-year period, Hanson et al. (2007) used the SR method and other measurements in a water-short area (Eq. (2)) to investigate the effect of deficit irrigation of alfalfa on the yield and evaporation. The performance of an ecosystem evaporation model was investigated using SR measurements of sensible heat flux at a wetlands site (Spano et al., 2009). Bare-soil evaporation was modelled using a coupled heat, water vapour and liquid water flux model and the modelled estimates compared with that using the SR method and energy balance measurements (Eq. (2)) (Bittelli et al., 2008).
Noting that that the BREB method is not recommended for locations influenced by regional advection, and using the SR-similarity combination approach, Castellví and Snyder (2009b) used SR analysis to estimate sensible heat flux over 2 growing rice fields under regional advection.

Of particular relevance to studies for which there are fetch limitations, Paw U et al. (1995) demonstrated that for short canopies, there was an indication that the SR method was not sensitive to inadequate fetch. They also concluded that the SR method decreased in accuracy as height above the (maize) canopy increased.

The SR method has also been applied to flux estimates of latent energy and carbon dioxide (Castellví et al., 2008). In this investigation, surface energy balance closure over rangeland grass, using SR measurements of $H$ and $\lambda E$, by application of Eq. (18), was investigated and compared with EC closure. The EC method consistently underestimated the available energy flux $\left(R_{n}-G\right.$ of Eq. (2)) by about $10 \%$ whereas the SR closure was always good.

For measurements in a peach orchard and using the SR/ similarity theory combination method (Eq. (19)), Castellví and Snyder (2009c) found that for unstable cases, $H_{S R}$ underestimated by about $7 \%$ and as a result, the sign of the ramp amplitude $a$ was not in agreement with the sign of $H_{E C}$. They concluded that their experiment demonstrated the potential of SR as a method applicable at any height above the canopy surface for estimating $H$.

\section{Recommendations for future research}

The SR method is relatively new and quite simple (Paw et al., 1995; Snyder et al., 1996; Spano et al., 2000). The advantages of the SR method over other micrometeorological methods are the relatively low cost, easy installation and maintenance; apparently the method is less dependent on fetch since it is based on the theory of short-term heat transfer between a surface and that it operates in the roughness and inertial sub-layers. The ideal SR method is the most inexpensive micrometeorological method for estimating sensible heat flux, but the SR weighting factor $\alpha$ needs to be determined using a standard method such as the eddy covariance method. At least two calibrations are recommended: one for night-time and one for day-time conditions to better account for stability conditions. In South Africa, the SR method has been evaluated by Savage et al. (2004), Mengistu (2008) and Nile (2010) for a wide range of canopies and above water (Mengistu and Savage, 2010). Savage (2007) suggested that high frequency air-temperature-based methods may pave the way for evaporation stations from which real-time and sub-hourly estimates may be obtained relatively inexpensively.

The SR method has mostly been used for estimating sensible heat flux over different surfaces, and the latent energy flux obtained as a residual of the energy balance (Eq. (2)). The latter provides the most inexpensive procedure to estimate latent energy flux (Drexler et al., 2004).

The SR analysis can be applied to other scalars such as water vapour pressure, carbon dioxide concentration, and other gas concentrations. However, there has been little research on the application of the SR analysis to estimate the flux of other scalars. Currently there are very few published works detailing the application of SR analysis to determine latent energy flux (Katul et al., 1996; Castellví et al., 2008) and only 2 for carbon dioxide (Spano et al. 2002; Castellví et al., 2008). Therefore, further studies should focus on the use of the SR method to 
estimate fluxes of water vapour, carbon dioxide, and other scalars. Also, the SR method applied here does not allow realtime estimation of sensible heat flux and further research on this aspect would be valuable for long-term monitoring. The SR methods that are exempt from calibration need to be applied to other surfaces to confirm their applicability over a wide range of atmospheric and surface conditions.

\section{Acknowledgements}

Funding from the University of KwaZulu-Natal, CSIR, and Water Research Commission (part of WRC Projects No. K1335 and No. K1567) for this study is gratefully acknowledged.

\section{References}

ANANDAKUMAR K (1999) Sensible heat flux over a wheat canopy: optical scintillometer measurements and surface renewal analysis estimations. Agric. For. Meteorol. 96 145-156.

ARYA SP (2001) Introduction to Micrometeorology ( $2^{\text {nd }}$ edn.) Academic Press. London, UK. 420 pp.

BERGSTRÖM H and HÖGSTRÖM U (1989) Turbulent exchange above a pine forest: II. Organized structures. Boundary-Layer Meteorol. 49 231-263.

BEZUIDENHOUT CN, LECLER NL, GERS C and LYNE PWL (2006) Regional based estimates of water use for commercial sugar-cane in South Africa. Water SA 32 219-222.

BITTELLI M, VENTURA F, CAMPBELL GS, SNYDER RL, GALLEGATI F and PISA PR (2008) Coupling of heat, water vapor, and liquid water fluxes to compute evaporation in bare soils. J. Hydrol. 362 191-205.

BUSINGER JA, WYNGAARD, JC, IZUMI I and BRADLEY EF (1971) Flux profile relationships in the atmospheric surface layer. J. Atmos. Sci. 28 181-189.

CAMPBELL GS and DIAK GR (2005) Net and thermal radiation estimation and measurement. In: Hatfield JL and Baker JM (eds.) Micrometeorology in Agricultural Systems. Agronomy Monograph No. 47. 59-92.

CASTELLVÍ F (2004) Combining surface renewal analysis and similarity theory: a new approach for estimating sensible heat flux. Water Resour. Res. 40 W05201, 1-20.

CASTELLVÍ F (2007) The estimation of latent heat flux: a reflection for the future. Tethys 4 19-26.

CASTELLVÍ F (2009) Some advance on the comprehension of SR analysis for estimating the flux of a scalar. Geophys. Res. Abstr. 11 EGU2009-2251-1.

CASTELLVÍ F and MARTÍNEZ-COB A (2005) Estimating sensible heat flux using surface renewal analysis and flux variance method: A case study over olive trees at Sastago (NE of Spain). Water Resour. Res. 41 W09422, 1-10.

CASTELLVÍ F and SNYDER RL (2009a) Combining the dissipation method and surface renewal analysis to estimate scalar fluxes from the time traces over rangeland grass near Ione (California). Hydrol. Process. 23 842-857.

CASTELLVÍ F and SNYDER RL (2009b) On the performance of surface renewal analysis to estimate sensible heat flux over two growing rice fields under the influence of regional advection. J. Hydrol. 375 546-553.

CASTELLVÍ F and SNYDER RL (2009c) Sensible heat flux estimates using surface renewal analysis A study case over a peach orchard. Agric. For. Meteorol. 149 1397-1402.

CASTELLVÍ F, MARTÍNEZ-COB A and PEREZ-COVETA O (2006a) Estimating sensible and latent heat fluxes over rice using surface renewal. Agric. For. Meteorol. 139 164-169.

CASTELLVÍ F, PEREZ PJ and IBAÑEZ M (2002) A method based on high frequency temperature measurements to estimate sensible heat flux avoiding the height dependence. Water Resour. Res. 38 (6) WR000486-20, 1-10.

CASTELLVÍ F, SNYDER RL and BALDOCCHI DD (2008) Surface energy-balance closure over rangeland grass using the eddy covariance method and surface renewal analysis. Agric. For. Meteorol. 148 1147-1160.

CASTELLVÍ F, SNYDER RL, BALDOCCHI DD and MARTÍNEZCOB (2006b) A comparison of new and existing equations for estimating sensible heat flux using surface renewal and similarity concepts. Water Resour. Res. 42 W08406, 1-18.

CHEN W, NOVAK MD, BLACK TA and LEE X (1997a) Coherent eddies and temperature structure functions for three contrasting surfaces. Part I: Ramp model with finite micro front time. Boundary-Layer Meteorol. 84 99-123.

CHEN W, NOVAK MD, BLACK TA and LEE X (1997b) Coherent eddies and temperature structure functions for three contrasting surfaces. Part II: Renewal model for sensible heat flux. BoundaryLayer Meteorol. 84 125-147.

DE BRUIN HAR, VAN DEN HURK BJJM and KOHSIEK W (1995) The scintillation method tested over dry vine yard area. BoundaryLayer Meteorol. 76 25-40.

DREXLER JZ, SNYDER RL, SPANO D and PAW U KT (2004) A review of models and micrometeorological methods used to estimate wetland evapotranspiration. Hydrol. Process. 18 2071-2101.

DUCE P, SPANO D and SNYDER RL (1998) Effect of different finewire thermocouple design on high frequency temperature measurement. In: AMS Proc. 23rd Conf. Agric. For. Meteorol. 2-6 Nov. Albuquerque, NM. 146-147.

DUCE P, SPANO D, SNYDER RL and PAW U KT (1997) Surface renewal estimates of evapotranspiration. Short canopies. Acta Hort. 449 57-62.

GAO W, SHAW RH and PAW U KT (1989) Observation of organized structure in turbulent flow within and above a forest canopy. Boundary-Layer Meteorol. 47 349-377.

GREEN AE, MCANENEY KJ and ASTILL MS (1994) Surface layer scintillation measurements of daytime heat and momentum fluxes. Boundary-Layer Meteorol. 68 357-373.

HANSON B, PUTNAM D and SNYDER R (2007) Deficit irrigation of alfalfa as a strategy for providing water for water-short areas. Agric. Water Manage. 93 73-80.

HIGBIE R (1935) The rate of absorption of a pure gas into a still liquid during short periods of exposure. Trans. Am. Inst. Chem. Eng. 31 365-388.

HILL RJ (1992) Review of optical scintillation methods of measuring the refractive-index spectrum, inner scale and surface fluxes. Waves Random Media 2 179-201.

HILL RJ, OCHS JR and WILSON JJ (1992) Measuring surface layer fluxes of heat and momentum using optical scintillation. Boundary Layer Meteorol. 58 391-408.

HSIEH C-I and KATUL GG (1997) Dissipation methods, Taylor's hypothesis, and stability correction functions in the atmospheric surface layer. J. Geophys. Res. 102 16391-16405.

JARMAIN C, EVERSON CS, SAVAGE MJ, MENGISTU MG, CLULOW AD and GUSH MB (2009) Refining Tools for Evaporation Monitoring in Support of Water Resources Management. WRC Report No. 1567. Water Research Commission, Pretoria, South Africa. $137 \mathrm{pp}$.

KATUL GG, HSIEH C-I, OREN R, ELLSWORTH D and PHILIPS $\mathrm{N}$ (1996) Latent and sensible heat flux predictions from a uniform pine forest using surface renewal and flux variance methods. Boundary-Layer Meteorol. 80 249-282.

LEE X and BLACK TA (1993) Atmospheric turbulence within and above a Douglas-Fir stand. Part I: Statistical properties of the velocity field. Boundary-Layer Meteorol. 64 149-174.

MEDTHERM CORP (2007) Fine wire thermocouple probes for measuring transient gas temperature. URL: http://www.dr-kubelik.de/ infomaterial/TCFW\%20Brochure\%20B112.pdf (Accessed on 9 December 2009).

MEIJNINGER WML and DE BRUIN HAR (2000) The sensible heat fluxes over irrigated areas in western Turkey determined with a large aperture scintillometer. J. Hydrol. 229 42-49.

MENGISTU MG (2008) Heat and Energy Exchange above Different Surfaces using Surface Renewal. Ph.D. thesis. University of KwaZulu-Natal, Pietermaritzburg, South Africa. 151 pp.

MENGISTU MG and SAVAGE MJ (2010) Open water evaporation estimation for a small shallow reservoir in winter using surface 
renewal. J. Hydrol. 380 27-35.

NILE ES (2010) Sensible heat flux estimation for unstable conditions for sugarcane using temperature variance and surface renewal. Ph.D. thesis. University of KwaZulu-Natal, Pietermaritzburg, South Africa. 174 pp.

PAW U KT and BRUNET Y (1991) A surface renewal measure of sensible heat flux density. Proc. $20^{\text {th }}$ Conf. Agric. For. Meteorol, 10-13 September, Salt Lake City, UT. American Meteorological Society, Boston, MA. 52-53.

PAW U KT, BRUNET Y, COLLINEAU S, SHAW RH, MAITANI T, QUI J and HIPPS L (1992) On coherent structure in turbulence within and above agricultural plant canopies. Agric. For. Meteorol. 61 55-68.

PAW U KT, QUI J, SU HB, WATANABE T and BRUNET Y (1995) Surface renewal analysis: a new method to obtain scalar fluxes. Agric. For. Meteorol. 74 119-137.

PAW U KT, SNYDER RL, SPANO D and SU HB (2005) Surface renewal estimates of scalar exchange. In: Hatfield JL and Baker JM (eds.) Micrometeorology in Agricultural Systems. Agronomy Monograph. No. 47. 455-483.

QUI J, PAW U KT and SHAW RH (1995) Pseudo-wavelet analysis of turbulence patterns in three vegetation layers. Boundary-Layer Meteorol. 72 177-204.

RAUPACH MR, FINNIGAN JJ and BRUNET Y (1989) Coherent eddies in vegetation canopies. In: Proc. 4th Australasian Conf. on Heat and Mass Transfer. 9-12 May, Christchurch, New Zealand. Bergell House, New York. 75-90.

RAUPACH MR, FINNIGAN JJ and BRUNET Y (1996) Coherent eddies in vegetation canopies: The mixing-layer analogy. Boundary-Layer Meteorol. 78 351-382.

SAVAGE MJ (2007) Sensible heat estimation using a high frequency temperature-based method above various canopies. Proc. $13^{\text {th }} \mathrm{S}$ Afr. Nat. Chap. Int. Assoc. Hydro. Sci. (SANCIAHS) Symp. 6-7 September, Cape Town, Republic of South Africa.

SAVAGE MJ (2009) Estimation of evaporation using a dual-beam surface layer scintillometer and component energy balance measurements. Agric. For. Meteorol. 149 501-517.

SAVAGE MJ, EVERSON CS, ODHIAMBO GO, MENGISTU MG and JARMAIN C (2004) Theory and Practice of Evapotranspiration Measurement, with Special Focus on SLS as an Operational Tool for the Estimation of Spatially-Averaged Evaporation. WRC Report No. 1335/1/04. Water Research Commission, Pretoria, South Africa. 204 pp.

SAVAGE MJ, ODHIAMBO GO, MENGISTU MG, EVERSON CS, JARMAIN C (2010) Measurement of grassland evaporation using a surface-layer scintillometer. Water $S A 36$ (1) 1-8.

SELLERS PJ, MINTZ Y, SUD YC and DALCHER A (1986) A simple biosphere model ( $\mathrm{SiB})$ for use within general circulation models. J. Atmos. Sci. 43 505-531.

SHAW RH, PAW U KT and GAO W (1989) Detection of temperature ramps and flow structures at deciduous forest site. Agric. For. Meteorol. 47 123-138.
SIMMONS LJ, WANG J, SAMMIS TW and MILLER DR (2007) An evaluation of two inexpensive energy-balance techniques for measuring water use in flood-irrigated pecans. Agric. Water Manage. 88 181-191.

SNYDER RL, ANDERSON FE, SPANO D, DUCE P, PAW U KT and RUSSO AE (2007) An Excel Application Program to Compute Surface Renewal Estimates of Sensible Heat Flux from the 2nd, 3rd and 5th Moments of a Structure Function using High Frequency Temperature Data and to Compute ET and Crop Coefficients using Energy Balance. University of California, Davis, California.

SNYDER RL and O'CONNELL NV (2007) Crop coefficients for microsprinkler-irrigated clean-cultivated, mature citrus in an arid climate. J. Irrig. Drain. Eng. 133 43-52.

SNYDER RL, SPANO D, DUCE P and PAW U KT (1997) Surface renewal estimates of evapotranspiration. Theory. Acta Hort. 449 49-55.

SNYDER RL, SPANO D and PAW U KT (1996) Surface renewal analysis for sensible heat and latent heat flux density. BoundaryLayer Meteorol. 77 249-266.

SNYDER RL, SPANO D, DUCE P, PAW U KT and RIVERA M (2008) Surface renewal estimation of pasture evapotranspiration. J. Irrig. Drain. Eng. 134 716-721.

SPANO D, DUCE P, SNYDER RL and PAW U KT (1997a) Surface renewal estimates of evapotranspiration: tall canopies. Acta Hort. 449 63-68.

SPANO D, SNYDER RL, DUCE P and PAW U KT (1997b) Surface renewal analysis for sensible heat flux density using structure functions. Agric. For. Meteorol. 86 259-271.

SPANO D, SNYDER RL, DUCE P and PAW U KT (2000) Estimating sensible and latent heat flux densities from grape vine canopies using surface renewal. Agric. For. Meteorol. 104 171-183.

SPANO D, SNYDER RL, DUCE P, PAW KT and FALK M (2002) Surface renewal determination of scalar fluxes over an old-growth forest. Am. Meteorol. Soc. 104 171-183.

SPANO D, SNYDER RL, SIRCA C and DUCE P (2009) ECOWAT a model for ecosystem evapotranspiration estimation. Agric. For. Meteorol. 149 1584-1596.

STULL RB (1984) Transilient turbulence theory: 1. The concept of eddy-mixing across finite distances. J. Atmos. Sci. 41 3351-3367.

THIERMANN V and GRASSL H (1992) The measurement of turbulent surface-layer fluxes by use of bichromatic scintillation. Boundary-Layer Meteorol. 58 367-389.

THOM AS (1975) Momentum, mass and heat exchange in plant communities. In: Monteith JL (eds.) Vegetation and the Atmosphere. Principles. Academic Press. London, UK. Vol. 1. 57-109.

VAN ATTA CW (1977) Effect of coherent structures on structure functions of temperature in the atmospheric boundary layer. Arch. Mech. 29 161-171.

ZAPATA N and MARTÍNEZ-COB A (2001) Estimation of sensible and latent heat flux from natural sparse vegetation surface using surface renewal. J. Hydrol. 254 215-228. 
Available on website http://www.wrc.org.za ISSN 0378-4738 (Print) = Water SA Vol. 36 No. 1 January 2010 ISSN 1816-7950 (On-line $)=$ Water SA Vol. 36 No. 1 January 2010 